Erratum

\title{
Erratum to "Mediterranean Diet and Red Yeast Rice Supplementation for the Management of Hyperlipidemia in Statin-Intolerant Patients with or without Type 2 Diabetes"
}

\author{
Giovanni Sartore, ${ }^{1}$ Silvia Burlina, ${ }^{1}$ Eugenio Ragazzi, ${ }^{2}$ Stefania Ferraresso, ${ }^{1}$ \\ Romina Valentini, ${ }^{1}$ and Annunziata Lapolla ${ }^{1}$ \\ ${ }^{1}$ Department of Medicine (DIMED), University of Padua, Via Giustiniani 2, 35100 Padova, Italy \\ ${ }^{2}$ Department of Pharmaceutical and Pharmacological Sciences, University of Padua, Via Giustiniani 2, 35100 Padova, Italy \\ Correspondence should be addressed to Silvia Burlina; silvia.burlina@studenti.unipd.it
}

Received 5 March 2014; Accepted 5 March 2014; Published 13 March 2014

Copyright (C) 2014 Giovanni Sartore et al. This is an open access article distributed under the Creative Commons Attribution License, which permits unrestricted use, distribution, and reproduction in any medium, provided the original work is properly cited.

The authors' names were incorrectly listed as Sartore Giovanni, Burlina Silvia, Ragazzi Eugenio, Ferraresso Stefania, Valentini Romina, and Lapolla Annunziata; this error is corrected here. 


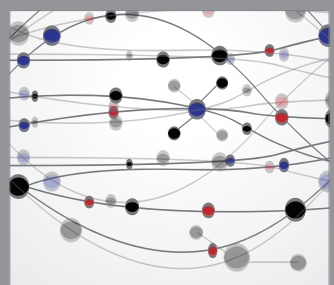

The Scientific World Journal
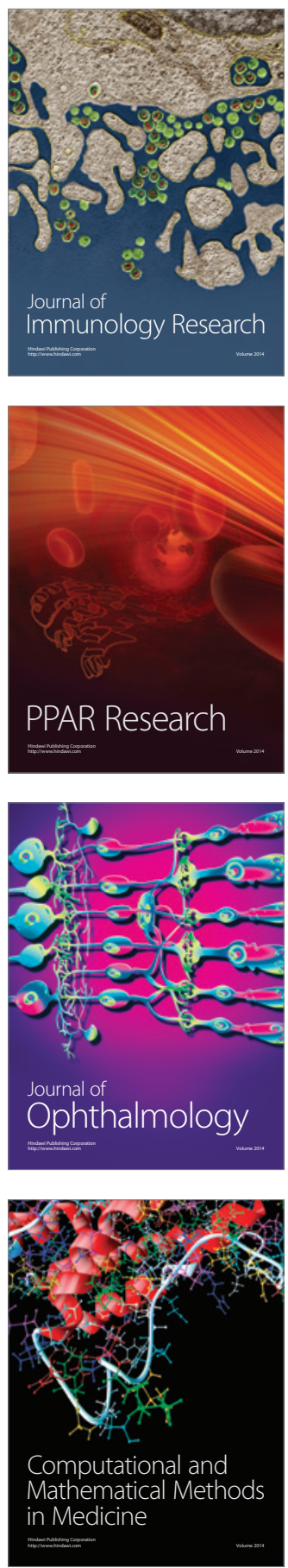

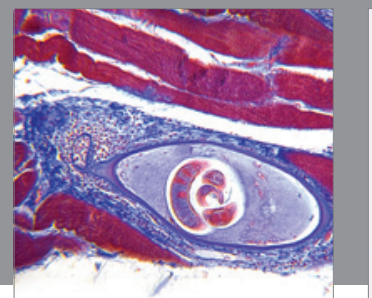

Gastroenterology

Research and Practice
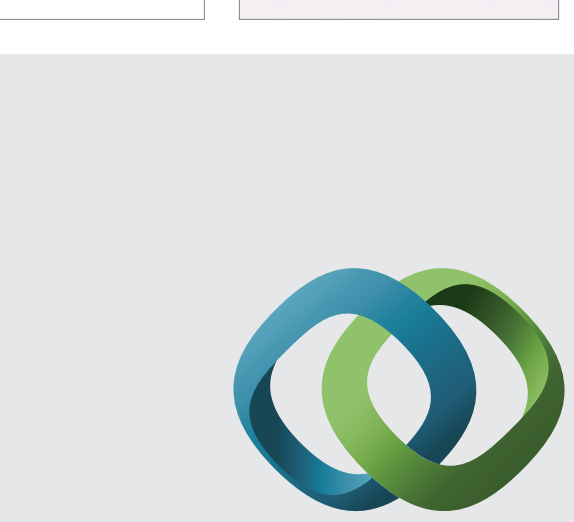

\section{Hindawi}

Submit your manuscripts at

http://www.hindawi.com
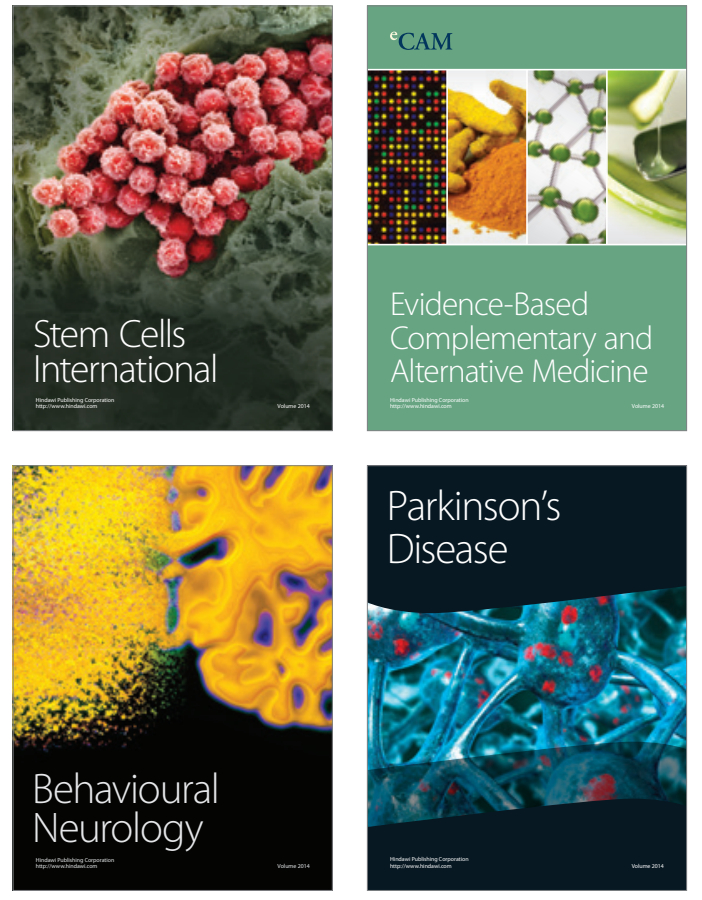
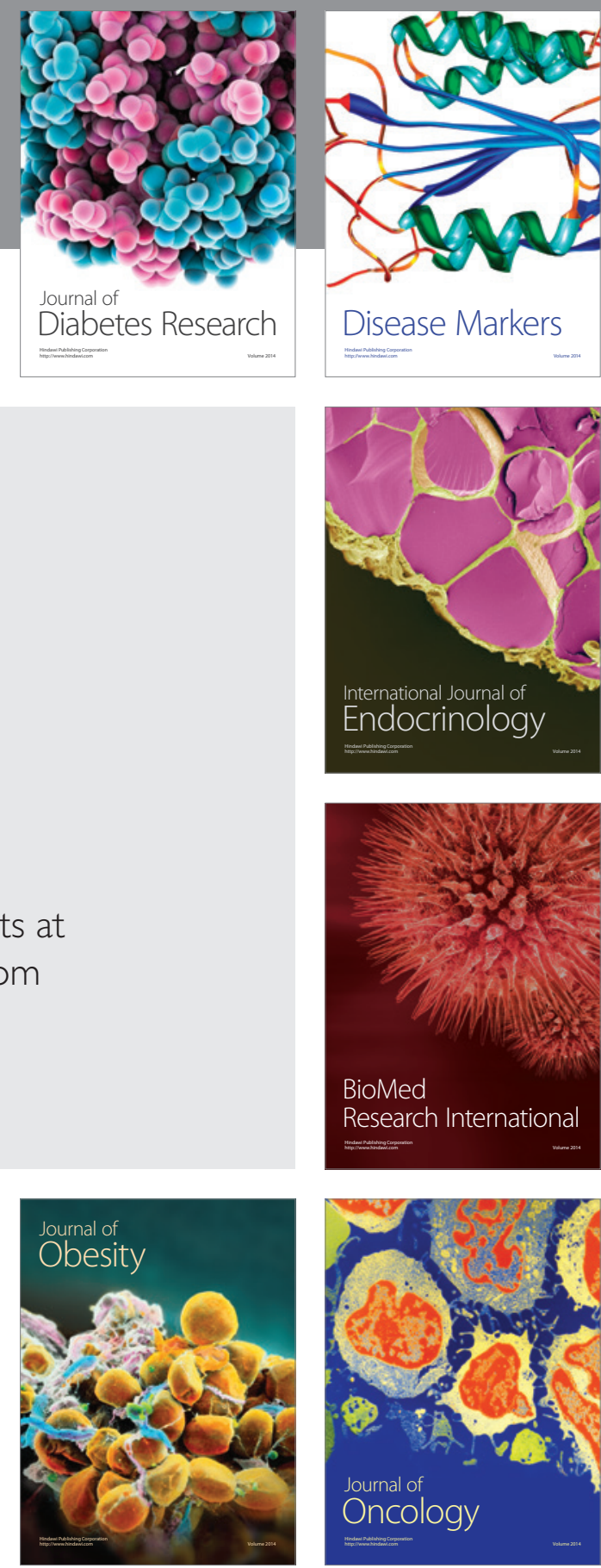

Disease Markers
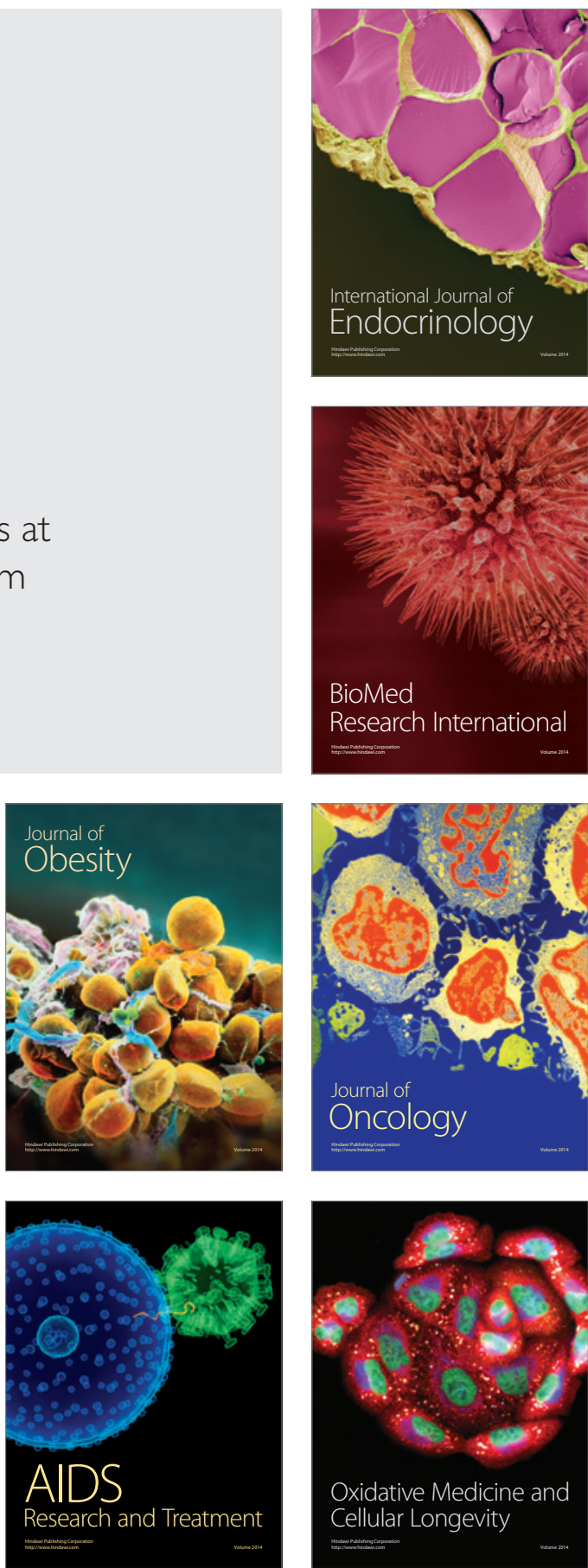